\title{
Less water renewal reduces effects on social aggression of the cichlid Pterophyllum scalare
}

\author{
Ana Carolina dos Santos Gauy ${ }^{\mathrm{a}, \mathrm{b}}$, Camila Nomura Pereira Boscolo ${ }^{\mathrm{a}, \mathrm{c}}$, \\ Eliane Gonçalves-de-Freitas ${ }^{\mathrm{a}, \mathrm{b}, *}$ \\ ${ }^{a}$ Departamento de Zoologia e Botânica, Instituto de Biociências, Letras e Ciências Exatas, Universidade Estadual Paulista, Cristóvão Colombo, 2265, 15054-000, São José \\ do Rio Preto, SP, Brazil \\ b Centro de Aquicultura da UNESP - CAUNESP, Brazil \\ c Centro Universitário de Rio Preto, Brazil
}

\section{A R T I C L E I N F O}

\section{Keywords:}

Chemical communication

Social rank

Ornamental fish

Welfare

\begin{abstract}
A B S T R A C T
Changes in aquatic environments can affect fish behavior. Water renewal, for example, can dilute chemical signals, which are a social communication tool used by some fish species, and this dilution increases aggressive interactions in the group. Fierce and prolonged fights can affect fish welfare by increasing the probability of injuries, stress, and detrimental impacts on fish health. We tested whether the amount of water changed was associated with social aggression in the angelfish Pterophyllum scalare, a popular ornamental Amazonian cichlid. We designed an experiment with social groups ( $3 \mathrm{fish}$ ) that were assigned to one of three treatments (with 15 replicates of each treatment): 1) 50\% water renewal; 2) $25 \%$ water renewal; or 3) $0 \%$ renewal (i.e., water removed and returned to the aquarium as a control). These treatments were referred to as $\mathrm{T} 50 \%$, T25\%, and T0\%, respectively. Fish behavior was video-recorded immediately before water renewal (baseline) and also $1 \mathrm{~min}, 1 \mathrm{~h}, 2 \mathrm{~h}$, and $24 \mathrm{~h}$ after water renewal. The frequencies of attacks (overt fights) and displays (threats) were compared using the general linear model (GLM), with the treatment as the categorical factor, observation sessions as the repeated measures, and social rank as a continuous factor. Attacks increased after the water was changed, and they were higher in $\mathrm{T} 50 \%$ than in $\mathrm{T} 25 \%(\mathrm{P}=0.0001)$. In T25\%, aggression returned to baseline levels after $1 \mathrm{~h}(\mathrm{P}=0.32)$, but remained increased after $24 \mathrm{~h}$ in $\mathrm{T} 50 \%(\mathrm{P}=0.000001)$. Changing only a small volume of water at a time was therefore found to prevent exaggerated aggressive interactions among $P$. scalare specimens and to reduce the probability of injuries, stress, and detrimental impacts on fish welfare.
\end{abstract}

\section{Introduction}

Animal welfare can be affected by changes in the rearing environment. Among fish, changes in the aquatic environment can directly affect several types of communication (Rosenthal and Lobel, 2006) and can have negative consequences on behavior, particularly because chemical communication is impaired by changes in water characteristics. Fish use chemicals to signal their reproductive state (Miranda et al., 2005; Stacey and Sorensen, 2006), to recognize conspecifics (Reebs, 1994; Thünken et al., 2009), to warn conspecifics of predators (Jordão and Volpato, 2000), to identify size (Giaquinto and Volpato, 2005), to find well-nourished males in sexual selection (Giaquinto, 2010), and to communicate social rank in a social hierarchy system (Giaquinto and Volpato, 1997; Gonçalves-de-Freitas et al., 2008). These signals are released with the urine (Hubbard et al., 2014) and with bile acids (Giaquinto et al., 2015). In aquaculture systems, water needs to be renewed to remove food leftovers, feces, and toxic nitrogen compounds, as well as to maintain adequate environmental quality for fish health (Goldstein, 2001). Water renewal in fishkeeping and aquaculture management can wash away chemical signals, resulting in social instability and increased aggressive interactions in the group (e.g. Gonçalves-de-Freitas et al., 2008).

Aggressive interaction is part of the natural behavior of several fish species (Damsgård and Huntingford, 2012). However, in some artificial circumstances, aggressive interaction becomes fierce and prolonged (e.g. Barreto et al., 2015; Boscolo et al., 2011). The subsequent fights cause bodily injury (Martins et al., 2012), fin damage and scale loss (Maan et al., 2001), increased stress levels (Boscolo et al., 2011; Huntingford et al., 2006), metabolic impairment (Sloman et al., 2000), and reduced probability of survival (Barreto et al., 2015). All of these

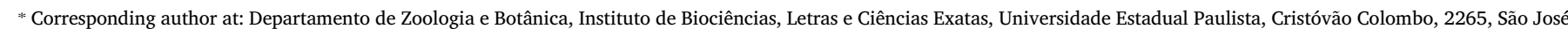
do Rio Preto, SP, 15054-000, Brazil.

E-mail addresses: ana.gauy@gmail.com (A.C.d.S. Gauy), nomuracamila@yahoo.com.br (C.N.P. Boscolo), elianeg@ibilce.unesp.br (E. Gonçalves-de-Freitas). 
changes present problems for fishkeeping (Damsgård and Huntingford, 2012), particularly among fish whose natural behavior includes competition for social rank. Therefore, finding ways to mitigate such effects is important both for fish welfare and for more successful aquaculture and fishkeeping.

Cichlids are commonly raised in aquaculture as finfish and for ornamental trade (Huntingford et al., 2012). Species from the family Cichlidae exhibit territorial behavior and form a spatial dominance hierarchy in which social rank is established by aggressive interactions (Turner and Huntingford, 1986). Social hierarchy is maintained by displays, which are behaviors that require low energy expenditure and which result in a low likelihood of injury. These displays also allow fish to recognize their social ranks and communicate them using a set of signals, including visual signals (e.g. Beeching, 1992; Boscolo et al., 2011; Korzan et al., 2008; Volpato et al., 2003), acoustic signals (Longrie et al., 2008), and chemical signals (Giaquinto and Volpato, 1997; Gonçalves-de-Freitas et al., 2008; Keller-Costa et al., 2015). When one or more signals are impaired, fish can not recognize social rank, and increased rates of aggression can therefore follow (Boscolo et al., 2011). Although cichlid species have a complex visual system (Fernald and Wright, 1985), chemical communication is crucial for many species of fish. Giaquinto and Volpato (1997), for example, showed that an interruption in the interchange of water between two contestants' aquaria caused Nile tilapia to continue fighting, and social rank was not established. Moreover, Gonçalves-de-Freitas et al. (2008) showed that continuous water renewal destabilized social hierarchy and increased attacks among Nile tilapia males by reducing the amount of information received by the subordinate fish. They also found that, after establishing their social rank, fish again escalated to overt fights after three hours-the point at which water renewal reached $50 \%$. These findings suggest that, in conditions in which water is not continuously renewed, social hierarchy can be established again after some time, thus reducing aggressive interaction in the group. In ornamental trade fish, aquarium water needs to be changed and replaced by clean water (albeit not continuously) as part of environmental management. Still, there are many questions regarding water change practices. Could water dilution have a transient effect if a small quantity of water is renewed? Are aggressive interactions associated with the amount of water renewed? The hypothesis tested here is that the amount of water renewed affects the time required to re-establish social hierarchy. This study tested the effect of changes in aquarium water on aggressive behavior of the cichlid angelfish Pterophyllum scalare, a popular ornamental cichlid species (Huntingford et al., 2012). We predicted that the amount of water renewed would positively correlate with aggression among individuals. Thus, by knowing the effect of the amount of water changed during aquarium management, we can offer a way to reduce the detrimental effects of artificial environments on social fish.

\section{Methods}

\subsection{Fish housing}

Pterophyllum scalare Schultze 1823 juveniles were obtained from the ornamental fish facility at the Aquaculture Center of the Jaboticabal campus of São Paulo State University, or UNESP (Centro de Aquicultura da UNESP, Jaboticabal, São Paulo, Brazil). The fish were acclimated to the lab for 15 days in $500 \mathrm{~L}$ polypropylene tanks (ca. $1 \mathrm{fish} / 10 \mathrm{~L}$ ) with water at $28 \pm 1{ }^{\circ} \mathrm{C}$ and a 12L:12D light regime (from 7:00 a.m. to 7:00 p.m.). Juveniles were used because $P$. scalare is a monomorphic species, and it is difficult distinguish the sex by external traits. Aggressive interaction can be different for adult males and females, since androgen levels increase during adult life in males (Oliveira and Almada, 1998; Oliveira, 2004), although androgens are also increased in female cichlids (e.g. Renn et al., 2012; Taves et al., 2009; Tubert et al., 2012). The use of juveniles prevented the influence of sex on aggressive behavior, and their use was possible because juveniles exhibit aggressive interactions in this phase as well (Carvalho et al., 2012). Fish were fed TetraColor Tropical Fish Food Granules (Tetra) twice a day (8:00 a.m. and 6:00 p.m.) until apparent satiation. Water quality was maintained using biological filters (Canister; filtering $400 \mathrm{~L} / \mathrm{h}$ ) and constant aeration.

\subsection{Experimental design}

The effect of different amounts of water renewal on aggressive interaction was tested in social groups of three angelfish (ranked as alpha, beta, and gamma fish) whose sex was not identified. The fish ranged from 30 to $50 \mathrm{~mm}$ in standard length (SL) and $0.5-5.5 \mathrm{~g}$ in weight. The social groups were formed and were observed once a day for four days to identify social rank establishment. On the fourth day, the social groups were randomly assigned to one of three treatments: 1) $0 \%$ water renewal (control); 2) $25 \%$ water renewal; or 3) $50 \%$ water renewal, treatments hereby referred to as $\mathrm{T} 0 \%, \mathrm{~T} 25 \%$, and $\mathrm{T} 50 \%$, respectively. The highest water change was based on Gonçalves-de-Freitas et al. (2008), who found that Nile tilapia increased aggressive interactions after $50 \%$ water renewal; half of this amount $(25 \%)$ was therefore chosen to test for water renewal at a smaller volume. In all treatments, $50 \%$ of the water volume was removed from the aquarium through a plastic tube placed inside the aquaria. In T0\%, the same water taken from the aquarium was returned to it as a control. In T25\%, half of the water returned to the aquaria was clean water and half was the original water, resulting in $25 \%$ renewed water. In T50\%, the water returned to the aquarium was $100 \%$ clean water, meaning that, after the treatment, $50 \%$ of the water in the tank was original and $50 \%$ was clean water.

The water handling process lasted the same amount of time in all treatments $(\sim 10 \mathrm{~min})$. Clean water was collected from a fish-free aquarium similar to those used in the tests, with a biological filter and aeration and at the same temperature. The water was gently poured in using a glass beaker so that interference with fish behavior would be minimized. We tested 15 replicates (social groups) of each treatment. As a result, 135 fish were used in this study.

\subsection{Aggressive interactions}

In aggressive interactions between pairs, subordinate fish death can result from continuous and one-directed strikes from the dominant fish. Thus, social groups of 3 fish were used, as this is the minimum number of individuals required to form a representative social hierarchy without risk of death. Fish were grouped together for three days, which has been determined to be sufficient time for $P$. scalare to establish a social hierarchy (Gómez-Laplaza and Morgan, 2003). On the fourth day, the aggressive behavior was recorded immediately before the water was changed or handled (the baseline amount), and then $1 \mathrm{~min}$, $1 \mathrm{~h}, 2 \mathrm{~h}$, and $24 \mathrm{~h}$ after the water was changed to evaluate the effect of this change on aggressive interactions at several time intervals, and also to evaluate the recovery time to baseline aggression levels. The video recordings lasted $10 \mathrm{~min}$ and were always run between 2:00 p.m. and 6:00 p.m. to avoid possible influences from circadian rhythm (as recommended by Martin and Bateson, 2007). This period was chosen because it was long after the first feeding (8:00 a.m.), which prevented any influence from food competition (Gómez-Laplaza and Morgan, 2003; Grobler and Wood, 2013). The fish were recorded on camcorders (Sony High-Definition Handycam), which were placed on tripods in front of each aquarium.

The aggressive behaviors were based on the ethogram described by Carvalho et al. (2012) for P. scalare, and included chases, lateral threats, frontal displays, undulation, nipping, and mouth fights. Aggressive behavior was labeled either as attacks (nipping, mouth fights, and chases) or as displays (lateral threats, undulation, and frontal displays). Attacks are overt fights that involve direct physical contact and are usually followed by elevated energy expenditure, whereas displays are moments of aggressive which do not involve physical contact and 
which are usually followed by reduced energy expenditure (Haller and Wittenberger, 1988; Ros et al., 2006). The frequency of attacks is higher as rank is being established, but this frequency decreases after rank is determined (Haller and Wittenberger, 1988; Johnsson et al., 2006). Meanwhile, the frequency of displays is lower during social rank establishment and increases thereafter (Haller and Wittenberger, 1988; Johnsson et al., 2006). This classification was useful for testing whether water renewal affected one or both types of aggressive behavior. Only one observer quantified the behavior, and quantification began when intraobserver reliability reached $95 \%$.

\subsection{Establishing social rank}

Social rank was inferred by an individual dominance index (DI $=$ the number of aggressive interactions performed by an individual divided by the number of aggressive interactions of the group), as was used by Gonçalves-de-Freitas et al. (2008). DI ranges from 0 to 1.0 , and the DI of dominant fish is higher than that of subordinate fish. Dominance includes both types of behavior (attacks and displays); therefore, DI was calculated using all aggressive interactions (Lehner, 1996). This index tends to be similar among individuals before rank is established, and it subsequently increases among dominant fish and decreases among subordinate fish (Gonçalves-de-Freitas et al., 2008; Lehner, 1996; Oliveira and Almada, 1996). In this study, DIs were determined for each rank on each of the three days before the water handling process, and immediately before the water was changed or handled on the fourth day (baseline session).

\subsection{Details of the experiment}

Before being grouped together, the animals were netted from $500 \mathrm{~L}$ tanks, anesthetized with benzocaine (Sigma-Aldrich, China; $12.8 \mathrm{mg} / \mathrm{L}$; e.g. Carvalho et al., 2012), weighed, and measured. They were then grouped together by size. Respective mean ( \pm SE) values for SL and weight of the fish in the different treatment groups are shown in Table 1. There were no significant differences in SL or weight between treatments (Table 1). Also, the respective intragroup coefficients of variation in length and weight in each treatment group were not significant (Table 1).

The animals were individually identified by natural body color patterns (e.g. Carvalho et al., 2012). They were observed in aquaria $(400 \times 300 \times 400 \mathrm{~mm}$; ca. $48 \mathrm{~L})$ with three walls covered by an opaque blue plastic to avoid visual contact with animals from adjacent aquaria, though the frontal portion of the tank lacked the plastic covering to allow for video recordings. The blue color was chosen because it reduces cortisol levels in cichlid species (Maia and Volpato, 2013). Water temperature was set at $28 \pm 1{ }^{\circ} \mathrm{C}$, and the light regime was 12L:12D (light from 7:00 a.m. to 7:00 p.m.). Water oxygen was maintained at $8.24 \pm 0.64 \mathrm{ppm}$, and $\mathrm{pH}$ was maintained at $7.0 \pm 0.1$. Ammonia and nitrite levels, which were measured at the end of the experiments using LabconTest commercial kits, were, respectively: $0 \mathrm{ppm}$ and $0.25 \pm 0.08 \mathrm{ppm}$ in $\mathrm{T} 0 \%$; $0 \mathrm{ppm}$ and $0.1 \pm 0.06 \mathrm{ppm}$ in

\section{Table 1}

Standard length (SL) and weight of the fish used in the study and the intragroup coefficients of variation (CV) in SL and weight in each treatment. Data are shown as mean \pm SE. Each variable was compared between treatments using one-way ANOVA.

\begin{tabular}{clllll}
\hline & T0\% & T25\% & T50\% & $F_{(2.42)}$ & $P$ value \\
\hline $\begin{array}{c}\text { Standard length } \\
\text { (mm) }\end{array}$ & $36.24 \pm 1.4$ & $38.24 \pm 1.4$ & $35.31 \pm 1.0$ & 1.40 & 0.26 \\
$\begin{array}{c}\text { CV of standard } \\
\text { length (\%) }\end{array}$ & $3.1 \pm 0.2$ & $2.4 \pm 0.1$ & $2.8 \pm 0.2$ & 1.90 & 0.15 \\
$\begin{array}{c}\text { Weight (g) } \\
\text { CV of body } \\
\text { weight (\%) }\end{array}$ & $7.10 \pm 0.23$ & $2.78 \pm 0.31$ & $2.57 \pm 0.18$ & 2.02 & 0.15 \\
& & $9.4 \pm 1.7$ & $9.8 \pm 1.1$ & 0.59 & 0.55 \\
\hline
\end{tabular}

T25\%; and $0 \mathrm{ppm}$ and $0.1 \pm 0.1 \mathrm{ppm}$ in T50\%. The animals were fed with the same food used during the acclimation period, which corresponded to $3 \%$ biomass and which was provided twice a day (8:00 a.m. and 6:00 p.m.).

\subsection{Data analysis}

Data normality was tested using the Kolmogorov-Smirnov test (Ha and Ha, 2012; Lehner, 1996), and homoscedasticity was determined using the Fmax test (Zar, 1999). Because some data were not fit for the homoscedasticity test, they were transformed by square root $(x+0.5$; Zar, 1999). The DI, the number of attacks, and the number of displays in each social rank were compared in the days before the water was changed using the general linear model (GLM), in which social rank was a categorical factor and behavioral sessions represented the repeated measures. The treatments were also compared after rank order was established. The number of attacks and displays were again recorded $1 \mathrm{~min}, 1 \mathrm{~h}, 2 \mathrm{~h}$, and $24 \mathrm{~h}$ after the water was changed or handled, and the findings from before and after water renewal were compared using the GLM. This time, the treatment was the categorical variable, the behavior observation session was the repeated measure, and social rank (alpha, beta, or gamma) represented the continuous predictors. Fisher's LSD test was applied as a post hoc test. In all analyses, data are shown as mean \pm SE. Statistical significance was set at $\mathrm{P} \leq 0.05$.

\subsection{Ethical note}

This study was carried out in accordance with the ethical principles of the Brazilian National Council for the Control of Animal Experimentation (CONCEA) and was approved by the Ethics Committee for Animal Experimentation of the São José do Rio Preto campus of São Paulo State University, known locally as the Universidade Estadual Paulista (UNESP), in Brazil (permit number 077/2013). All fish handling was preceded by anesthesia, and substantial efforts were made to minimize animal suffering, as recommended by the Animal Behavior Society's Guidelines.

\section{Results}

Social hierarchy was quickly established in the four days preceding water handling, as shown in Fig. 1. There was statistically significant interaction between social rank and observation session in terms of DI $\left(\mathrm{F}_{(6396)}=11.33 ; \mathrm{P}<0.001\right)$. Alpha fish exhibited higher DIs than beta fish $(\mathrm{P}<0.001)$ and gamma fish $(\mathrm{P}<0.001)$, and beta fish exhibited higher DIs than gamma fish $(\mathrm{P}<0.001)$ starting on the first day (Fig. 1A). Alpha fish exhibited higher DIs in the fourth day than on the first day $(\mathrm{P}<0.001)$. Beta fish and gamma fish exhibited lower DIs on the fourth day than on the first day $(\mathrm{P}<0.009$; Fig. 1A).

There was also a statistically significant interaction between social rank and observation session in terms of attacks $\left(F_{(6396)}=7.59\right.$; $\mathrm{P}<0.001)$. Alpha fish performed significantly more attacks than beta fish $(\mathrm{P}<0.002)$ and gamma fish $(\mathrm{P}<0.001)$, and beta fish performed significantly more attacks than gamma fish $(\mathrm{P}<0.02)$ starting on the first day (Fig. 1B). Alpha fish performed significantly more attacks on the fourth day than on the first day $(\mathrm{P}<0.001)$. Beta fish and gamma fish maintained their frequencies of attacks over time (P > 0.06) (Fig. 1B).

Displays also differed between ranks and observation sessions (statistically significant interaction; $\mathrm{F}_{(6396)}=40.47, \mathrm{P}<0.001$ ). Alpha fish performed significantly more displays than beta fish $(\mathrm{P}<0.003)$ and gamma fish $(\mathrm{P}<0.001)$, and beta fish performed significantly more displays than gamma fish $(\mathrm{P}<0.01)$ starting on the first day (Fig. 1C). Alpha fish and beta fish performed significantly more displays on the fourth day than on the first day ( $\mathrm{P}<0.001$ ). Gamma fish maintained the frequency of their displays over time $(\mathrm{P}>0.5$; 

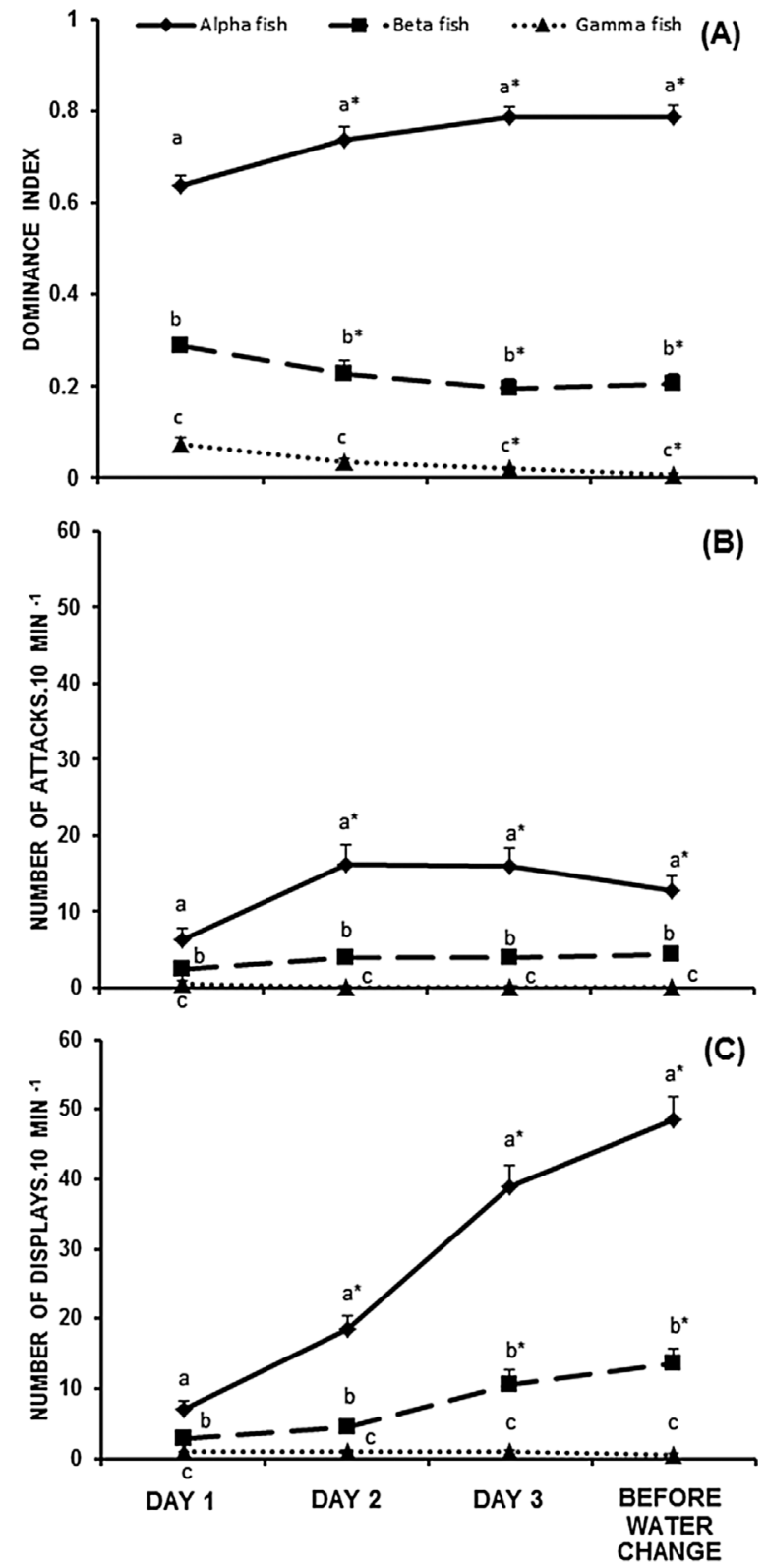

PERIODS

Fig. 1. Establishing social rank. Dominance index (A), number of attacks (B), and number of displays (C) by rank before aquarium water was changed. Data are mean \pm SE. Data have been collapsed across treatments. Letters compare means between ranks within each observation session. Values followed by at least one consistent letter did not differ significantly. Asterisks indicate significant differences within rank between the first and the fourth observation session (GLM followed by Fisher's LSD post hoc test).

Fig. 1C), findings which agree with the process of establishing a hierarchy. The fourth observation session was the baseline for comparisons before the water was changed.

\subsection{Attacks}

The amount of water changed had a clear effect on aggressive interactions among $P$. scalare individuals (Fig. 2A). A statistically significant correlation between treatment and observation sessions was found in terms of the number of attacks (GLM analysis; $F_{(8524)}=11.75$ $\mathrm{P}<0.001$ ), and Fisher's LSD post hoc test was then applied. The findings were compared within treatments: the number of attacks 1 min after the water was handled was similar to the baseline in $\mathrm{T} 0 \%$ ( $P$ > 0.075). In T25\%, attacks increased 1 min after water renewal

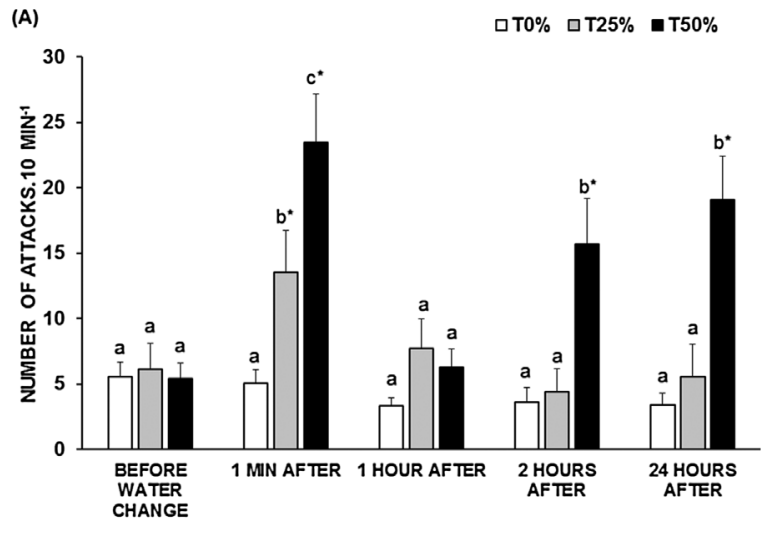

(B)

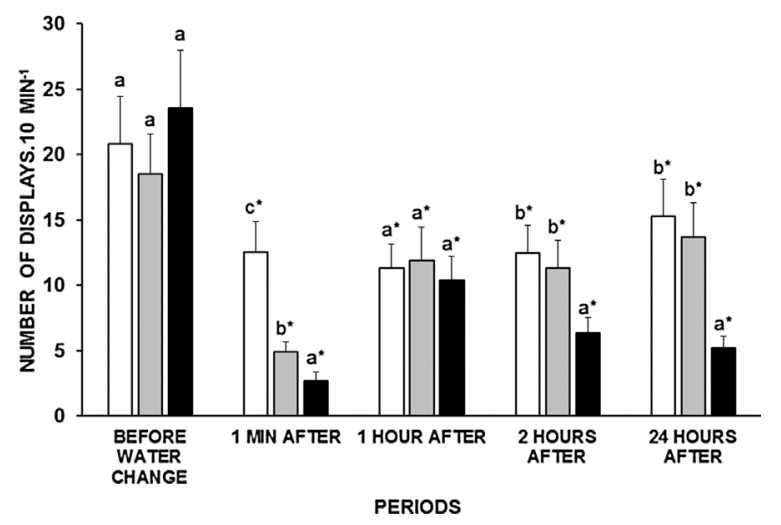

Fig. 2. Number (mean \pm SE) of attacks (A) and displays (B) following water renewal in the treatments. Letters reflect comparisons between treatments. Values followed by at least one consistent letter did not differ significantly. Asterisks indicate significant differences within treatments relative to baseline, defined as the period before the water was changed (GLM followed by Fisher's LSD post hoc test).

$(\mathrm{P}<0.001)$, decreased to baseline levels $1 \mathrm{~h}$ after the water was changed $(P=0.32)$, and remained at the baseline levels until the last session $24 \mathrm{~h}$ later $(\mathrm{P}>0.18)$. In T50\%, attacks increased $1 \mathrm{~min}$ after water renewal $(\mathrm{P}<0.001)$, decreased to baseline $1 \mathrm{~h}$ after water renewal $(\mathrm{P}=0.48)$, and increased again $2 \mathrm{~h}(\mathrm{P}<0.001)$ and $24 \mathrm{~h}$ $(\mathrm{P}<0.001)$ after the water was changed.

When the treatments were compared to each other, the number of attacks were found to be similar among all treatments immediately before the water was handled $(\mathrm{P}>0.73$ ) but differed significantly after the water was changed. In T25\%, attacks were more frequent than in the control $1 \mathrm{~min}$ after the water was changed $(\mathrm{P}<0.001)$, but they were less frequent than in T50\% (P $<0.001)$. One hour after the water was handled, the numbers of attacks were similar among the three test treatments $(\mathrm{P}>0.08)$. Two hours after the water was handled, only T50\% exhibited a significantly higher number of attacks relative to the control (T0\%), though this number was also significantly higher than the number of attacks in T25\% ( $\mathrm{P}<0.001)$. T0\% and T25\% were similar $(\mathrm{P}=0.96)$. The same result was observed after $24 \mathrm{~h}$ : attacks in $\mathrm{T} 50 \%$ were more frequent than in $\mathrm{T} 0 \%(\mathrm{P}<0.001)$ and $\mathrm{T} 25 \%$ $(\mathrm{P}<0.001)$, and T0\% and T25\% results were similar $(\mathrm{P}=0.89)$.

\subsection{Displays}

The amount of water changed also affected displays (Fig. 2B). A statistically significant interaction between treatments and observation sessions in terms of the number of displays was found (GLM analysis; F $(8524)=6.09 ; \mathrm{P}<0.001)$. The comparison within treatments revealed a significant reduction in displays $1 \mathrm{~min}$ after water renewal in T0\% $(P<0.001)$, which remained similar to all of the other sessions 
( $\mathrm{P}>0.10$ ). In $\mathrm{T} 25 \%$, displays decreased $1 \mathrm{~min}$ after water renewal $(\mathrm{P}<0.001)$ to a value which was lower than those of the remaining sessions $(\mathrm{P}<0.013)$. The number of displays increased again $1 \mathrm{~h}$ after the water was changed $(\mathrm{P}<0.001)$ and remained increased until the last reading $24 \mathrm{~h}$ later $(\mathrm{P}>0.21)$. An opposite effect was observed in $\mathrm{T} 50 \%$. All post-handling display frequencies were lower after the water was changed $(\mathrm{P}<0.001)$, but there was some variation during the post-renewal observation sessions. Displays decreased after $1 \mathrm{~min}$ $(\mathrm{P}<0.001)$, increased after $1 \mathrm{~h}$ relative to the first minute $(\mathrm{P}<0.001)$, and remained similar after $24 \mathrm{~h}(\mathrm{P}=0.48)$.

When the treatments were compared to each other, a similar number of displays were found among the treatments at baseline ( $\mathrm{P}>0.55$ ). After $1 \mathrm{~min}$, the number of displays was lower in $\mathrm{T} 25 \%$ than in T0\% ( $\mathrm{P}<0.001)$, and T50\% was lower than both T25\% and T0\% $(\mathrm{P}<0.048)$. The numbers of displays were similar among the three treatments $1 \mathrm{~h}$ after the water was changed or handled $(\mathrm{P}>0.63)$. After $2 \mathrm{~h}$, display quantities were similar in $\mathrm{T} 0 \%$ and $\mathrm{T} 25 \%(\mathrm{P}=0.37)$, but there were fewer displays in $\mathrm{T} 50 \%$ than in the other two treatments $(\mathrm{P}<0.01)$. The same finding was observed after $24 \mathrm{~h}$, at which time displays in $\mathrm{T} 0 \%$ and $\mathrm{T} 25 \%$ were similar $(\mathrm{P}=0.42)$ and lower in $\mathrm{T} 50 \%(\mathrm{P}<0.001)$.

\section{Discussion}

Tank or aquarium water management focuses on the removal of food leftovers, feces, and accumulated nitrogen compounds, but these processes have a negative effect on some species of social fish. The water-changing process (i.e., replacing part of the water with clean water) changes the aquatic environment and increases aggressive interactions. This study has shown that water renewal increases aggressive interactions among $P$. scalare and that this effect is more intense and prolonged when a higher amount of water is renewed. Thus, the effect of the water-changing process on aggressive interactions can be minimized by changing small quantities of water at a time, at least in the case of the cichlid $P$. scalare.

In the first four days of this study, the DIs remained similar among the treatments. This index is usually applied to determine fish social rank and stability; the higher the DI, the higher the fish's status (Gonçalves-de-Freitas et al., 2008; Lehner, 1996). On the fourth day, the amounts of both attacks and displays differed significantly between alpha, beta, and gamma fish. The gamma fish exhibited fewer fights than expected, a result which was likely affected by their previous experience (e.g. Nelissen and Andries, 1988; Oliveira et al., 2009). The number of attacks was low during the first 4 days, and displays increased during this time, a finding which is representative of the hierarchy establishment process (Haller and Wittenberger, 1988). Therefore, the fourth day was considered to be the baseline. This baseline condition shows that all treatments started from the same level of aggression; therefore, it can be deduced that the results were due to water changes, and not to any previous conditions.

When $25 \%$ of the water was changed in the aquarium, the frequency of attacks increased immediately. However, one hour later, attacks decreased to baseline levels. The opposite occurred in the case of displays, which decreased after the water was handled and then increased again, and, in doing so, followed a natural response of ritualized fighting (Johnsson et al., 2006), similar to the behaviors observed in the four days preceding water changes. However, when the water change was higher (T50\%), the attacks increased even more than when less water was changed (T25\%), a finding which shows that the increase in attacks is associated with the amount of aquarium water changed. Nevertheless, one hour after water renewal, the frequency of attacks decreased abruptly. According to Matsumasa and Murai (2005), overt fighting generates an accumulation of lactate, which triggers a reduction in overt fights, and consequently, a decrease in extra energy expenditure (Briffa and Elwood, 2001; Neat et al., 1998). That point (1 h after handling) seems to reflect the effect described by these authors, and suggests that the fish were recovering from fighting requiring a high energy expenditure.

Fox et al. (1997) showed that cortisol levels are dependent on both an individual's social rank and social stability in the African cichlid fish Astatotilapia burtoni, a finding which reflects the negative effects of prolonged aggressive interactions. Understanding the mechanisms regulating social interactions among fish raised in artificial environments has important implications for animal welfare (Boscolo et al., 2011; Conte, 2004; Sloman et al., 2011). The results obtained herein suggest that the social interactions observed in this study are linked to the chemical signals released in the water, which were likely washed way when the water was changed, a process which probably disrupted fish communication.

Many fish species use chemicals released into the water as cues for communicating social status. Among the Nile tilapia (O. niloticus), the absence of chemical information increases aggressive interaction (Giaquinto and Volpato, 1997) and a constantly renewed water flow increases attacks from subordinate fish and destabilizes the social hierarchy (Gonçalves-de-Freitas et al., 2008), findings which indicate that chemical information is involved in social status recognition. Another cichlid, Astatotilapia burtoni, releases urine during territorial intrusion, a process which can be understood as a way to chemically establish social status (Maruska and Fernald, 2012). Almeida et al. (2005) also demonstrated that males of the Mozambique tilapia (Oreochromis mossambicus) signal their social rank by releasing urine in the water, and a sterol-like odorant is understood to be the chemical that communicates a male's social dominance (Barata et al., 2008). No chemical compounds were investigated in the current study, but it can be inferred that some type of chemical communication could be involved in rank establishment among $P$. scalare. Thus, changing only small amounts of water at a time could reduce impairments in communication and could allow aggression to be reset to stable levels more quickly.

Aggressive interaction itself can't be considered a welfare indicator because it is a common behavior performed by several fish species, including cichlids and salmonids (Damsgård and Huntingford, 2012; Martins et al., 2012). However, it is well documented that social instability increases cortisol levels (Fox et al., 1997; Johnsson et al., 2006) and that increased attacks cause injury (Martins et al., 2012) and reduce survival (Barreto et al., 2015). High energy expenditure in fights and extra time spent on aggressive interactions can have negative effects on other essential activities, such as growth and reproduction. In coho salmon (Oncorhynchus kisutch), for instance, growth rate is negatively correlated with aggression, a finding which shows that these two characteristics cannot be maximized at the same time (Vøllestad and Quinn, 2003). Therefore, aggressive interactions can be considered a welfare indicator when fierce fighting remains above stable levels for a prolonged period. These findings collectively show that reducing water dilution and changing smaller amounts of water at a time are ways to mitigate the effects of environmental changes on aggressive interaction among fish.

\section{Conflicts of interest}

The authors declare no conflicts of interest.

\section{Acknowledgments}

The authors would like to thank Aquaculture Center of São Paulo State University (UNESP) for donating P. scalare specimens; as well as the editor and two anonymous reviewers for their comments, which helped to improve the manuscript. This research was supported by the São Paulo Research Foundation (FAPESP) in Brazil (No. 2013/09021$0)$. 


\section{References}

Almeida, O.G., Miranda, A., Frade, P., Hubbard, P.C., Barata, E.N., Canário, A.V.M., 2005. Urine as a social signal in the Mozambique tilapia (Oreochromis mossambicus). Chem. Senses 30, i309-i310.

Barata, E.N., Fine, J.M., Hubbard, P.C., Almeida, O.G., Frade, P., Sorensen, P.W., Canário, A.V.M., 2008. A sterol-like odorant in the urine of Mozambique tilapia males likely signals social dominance to females. J. Chem. Ecol. 34, 438-449.

Barreto, T.N., Boscolo, C.N.P., Gonçalves-de-Freitas, E., 2015. Homogeneously sized groups increase aggressive interaction and affect social stress in Thai strain Nile tilapia (Oreochromis niloticus). Mar. Freshw. Behav. Physiol. 48, 309-318.

Beeching, S.C., 1992. Visual assessment of relative body size in a cichlid fish, the Oscar, Astronotus ocellatus. Ethology 90, 177-186.

Boscolo, C.N.P., Morais, R.N., Gonçalves-de-Freitas, E., 2011. Same-sized fish groups increase aggressive interaction of sex-reversed males Nile tilapia GIFT strain. Appl. Anim. Behav. Sci. 135, 154-159.

Briffa, M., Elwood, R.W., 2001. Decision rules, energy metabolism and vigour of hermitcrab fights. Proc. R. Soc. Lond. B 268, 1841-1848.

Carvalho, T.B., Ha, J.C., Gonçalves-de-Freitas, E., 2012. Light intensity can trigger different agonistic responses in juveniles of three cichlid species. Mar. Freshw. Behav. Physiol. 45, 91-100.

Conte, F.S., 2004. Stress and the welfare of cultured fish. Appl. Anim. Behav. Sci. 86, 205-223.

Damsgård, B., Huntingford, F., 2012. Fighting and aggression. In: Huntingford, F., Jobling, M., Kadri, S. (Eds.), Aquaculture and Behavior. Willey-Blackwell, Oxford, pp. 248-285.

Fernald, R.D., Wright, S.E., 1985. Growth of the visual system in the African cichlid fish, Haplochromis burtoni: Accommodation. Vision Res. 25, 163-170.

Fox, H.E., White, S.A., Kao, M.H.F., Fernald, R.D., 1997. Stress and dominance in a social fish. J. Neurosci. 17, 6463-6469.

Gómez-Laplaza, L.M., Morgan, E., 2003. The influence of social rank in the angelfish, Pterophyllum scalare, on locomotor and feeding activities in a novel environment. Lab. Anim. 37, 108-120.

Giaquinto, P.C., Volpato, G.L., 1997. Chemical communication, aggression, and conspecific recognition in the fish Nile tilapia. Physiol. Behav. 62, 1333-1338.

Giaquinto,, P.C., Volpato,, G.L., 2005. Chemical cues related to conspecific size in pintado catfish, Pseudoplatystoma coruscans. Acta Ethol. 8, 65-69.

Giaquinto, P.C., Barreto, R.E., Volpato, G.L., Fernandes-de-Castilho, M., Gonçalves-deFreitas, E., 2015. Bile acids as potential pheromones in pintado catfish Pseudoplatystoma corruscans (Spix \& Agassiz, 1829): eletrophysiological and behavioral studies. Neotrop. Ichthyol. 13, 237-244.

Giaquinto, P.C., 2010. Female pintado catfish choose well-fed males. Behaviour 147, 319-332.

Goldstein, J.R., 2001. Angelfish: A Complete Pet Owner's Manual. Barron's Educational Series, Inc., New York.

Gonçalves-de-Freitas, E., Teresa, F.B., Gomes, F.S., Giaquinto, P.C., 2008. Effect of water renewal on dominance hierarchy of juvenile Nile tilapia. Appl. Anim. Behav. Sci. 112, 187-195.

Grobler, J.M.B., Wood, C.M., 2013. The physiology of rainbow trout in social hierarchies: two ways of looking at the same data. J. Comp. Physiol. B 183, 787-799.

Ha, R.R., Ha, J.C., 2012. Integrative Statistics for the Social \& Behavioral Sciences. SAGE Publications Inc, California.

Haller, J., Wittenberger, C., 1988. Biochemical energetics of hierarchy formation in Betta splendens. Physiol. Behav. 43, 447-450.

Hubbard, P.C., Mota, V.C., Keller-Costa, T., da Silva, J.P., Canário, A.V.M., 2014. Chemical communication in tilapia: a comparison of Oreochromis mossambicus with $O$ niloticus. Gen. Comp. Endocrinol. 207, 13-20.

Huntingford, F.A., Adams, C., Braithwaite, V.A., Kadri, S., Pottinger, T.G., Sandøe, P., Turnbull, J.F., 2006. Current issues in fish welfare. J. Fish. Biol. 68, 332-372.

Huntingford, F.A., Kadri, S., Jobling, M., 2012. Introduction: aquaculture and behaviour. In: Huntingford, F., Jobling, M., Kadri, S. (Eds.), Aquaculture and Behavior. WilleyBlackwell, Oxford, pp. 1-35.

Johnsson, J.I., Winberg, S., Sloman, K.A., 2006. Social interactions. In: Sloman, K.A. Wilson, R.W., Balshine, S. (Eds.), Behaviour and Physiology of Fish. Elsevier Inc., San Diego, pp. 151-196.

Jordão, L.C., Volpato, G.L., 2000. Chemical transfer of warning information in non-injured fish. Behaviour 137, 681-690.

Keller-Costa, T., Canário, A.V.M., Hubbard, P.C., 2015. Chemical communication in cichlids: a mini-review. Gen. Comp. Endocrinol. 221, 64-74.

Korzan, W.J., Robison, R.R., Zhao, S., Fernald, R.D., 2008. Color change as a potential behavioral strategy. Horm. Behav. 54, 463-470.
Lehner, P.N., 1996. Handbook of Ethological Methods, second ed. Cambridge University Press, Cambridge.

Longrie, N., Fine, M.L., Parmentier, E., 2008. Innate sound production in the cichlid Oreochromis niloticus. J. Zool. 275, 413-417.

Maan, M.E., Groothuis, T.G.G., Wittenberg, J., 2001. Escalated fighting despite predictors of conflict outcome: solving the paradox in a South American cichlid fish. Anim. Behav. 62, 623-634.

Maia, C.M., Volpato, G.L., 2013. Environmental light color affects the stress response of Nile tilapia. Zoology 116, 64-66.

Martin, P., Bateson, P., 2007. Measuring Behaviour: An Introductory Guide, third ed. Cambridge University Press, Cambridge.

Martins, C.I., Galhardo, L., Noble, C., Damsgård, B., Spedicato, M.T., Zupa, W., Beauchaud, M., Kulczykowska, E., Massabuau, J.C., Carter, T., Planellas, S.R., Kristiansen, T., 2012. Behavioural indicators of welfare in farmed fish. Fish. Physiol. Biochem. 38, 17-41.

Maruska, K.P., Fernald, R.D., 2012. Contextual chemosensory urine signaling in an African cichlid fish. J. Exp. Biol. 215, 68-74.

Matsumasa, M., Murai, M., 2005. Changes in blood glucose and lactate levels of male fiddler crabs: effects of aggression and claw waving. Anim. Behav. 69, 569-577.

Miranda, A., Almeida, O.G., Hubbard, P.C., Barata, E.N., Canário, A.V.M., 2005. Olfactory discrimination of female reproductive status by male tilapia (Oreochromis mossambicus). J. Exp. Biol. 208, 2037-2043.

Neat, F.C., Taylor, A.C., Huntingford, F.A., 1998. Proximate costs of fighting in male cichlid fish: the role of injuries and energy metabolism. Anim. Behav. 55, 875-882.

Nelissen, M.H.J., Andries, S., 1988. Does previous experience affect the ranking of cichlid fish in a dominance hierarchy? Ann. Soc. R. Zool. Belg. 118, 41-50.

Oliveira, R.F., Almada, V.C., 1996. On the (in)stability of dominance hierarchies in the cichlid fish Oreochromis mossambicus. Aggress. Behav. 22, 37-45.

Oliveira, R.F., Almada, V.C., 1998. Androgenization of dominant males in a cichlid fish: androgens mediate the social modulation of sexually dimorphic traits. Ethol 104, $841-858$.

Oliveira, R.F., Silva, A., Canário, A.V.M., 2009. Why do winners keep winning?: Androgen mediation of winner but not loser effects in cichlid fish. Proc. R. Soc. B 276, 2249-2256.

Oliveira, R.F., 2004. Social modulation of androgens in vertebrates: mechanisms and function. Adv. Study Behav. 34, 165-239.

Reebs, S.G., 1994. Nocturnal mate recognition and nest guarding by female convict cichlids (Pisces, Cichlidae, Cichlasoma nigrofasciatum). Ethol 96, 303-312.

Renn, S.C., Fraser, E.J., Aubin-Horth, N., Trainor, B.C., Hofmann, H.A., 2012. Females of an African cichlid fish display male-typical social dominance behavior and elevated androgens in the absence of males. Horm. Behav. 61, 496-503.

Ros, A.F.H., Becker, K., Oliveira, R.F., 2006. Aggressive behaviour and energy metabolism in a cichlid fish, Oreochromis mossambicus. Physiol. Behav. 89, 164-170.

Rosenthal, G.G., Lobel, P.S., 2006. Communication. In: Sloman, K.A., Wilson, R.W., Balshine, S. (Eds.), Behaviour and Physiology of Fish. Elsevier Inc., San Diego, pp. 39-79.

Sloman, K.A., Motherwell, G., O'Connor, K.I., Taylor, A.C., 2000. The effect of social stress on the Standard Metabolic Rate (SMR) of brown trout, Salmo trutta. Fish Physiol. Biochem. 23, 49-53.

Sloman, K.A., Baldwin, L., McMahon, S., Snellgrove, D., 2011. The effects of mixedspecies assemblage on the behaviour and welfare of fish held in home aquaria. Appl. Anim. Behav. Sci. 135, 160-168.

Stacey, N.E., Sorensen, P.W., 2006. Reproductive pheromones. In: Sloman, K.A., Wilson, R.W., Balshine, S. (Eds.), Behaviour and Physiology of Fish. Elsevier Inc., San Diego, pp. 359-412.

Taves, M.D., Desjardins, J.K., Mishra, S., Balshine, S., 2009. Androgens and dominance: sex- specific patterns in a highly social fish (Neolamprologus pulcher). Gen. Comp. Endocrinol. 161, 202-207.

Thünken, T., Waltschyk, N., Bakker, T.C.M., Kullmann, H., 2009. Olfactory self-recognition in a cichlid fish. Anim. Cogn. 12, 717-724.

Tubert, C., Lo Nostro, F., Villafañe, V., Pandolfi, M., 2012. Aggressive behavior and reproductive physiology in females of the social cichlid fish Cichlasoma dimerus. Physiol. Behav. 106, 193-200.

Turner, G.F., Huntingford, F.A., 1986. A problem for game theory analysis: assessment and intention in male mouthbrooder contests. Anim. Behav. 34, 961-970.

Vøllestad, L.A., Quinn, T.P., 2003. Trade-off between growth rate and aggression in juvenile coho salmon, Oncorhynchus kisutch. Anim. Behav. 66, 561-568.

Volpato, G.L., Luchiari, A.C., Duarte, C.R.A., Barreto, R.E., Ramanzini, G.C., 2003. Eye color as an indicator of social rank in the fish Nile tilapia. Braz. J. Med. Biol. Res. 36, 1659-1663.

Zar, J.H., 1999. Biostatistical Analyses, fourth ed. Prentice Hall, New Jersey. 